\title{
Autonomy, Equality, AND ACCESS To SEXUAL AND REPRODUCTIVE HEALTH CARE
}

\author{
ERIN NELSON ${ }^{*}$
}

\begin{abstract}
The focus of this article is on access to sexual and reproductive health care, an essential aspect of reproductive justice. Although the scope of the problem is unknown, there are reasons to question whether Canadian women are able to access reproductive and sexual health services such as contraception and abortion. The author discusses these issues, and the significance of additional barriers that Canada's First Nations, Metis, and Inuit women face in obtaining access to reproductive health care services. The author argues that providing meaningful access to sexual and reproductive health care is essential to ensuring women's reproductive autonomy, and must be part of any political endeavour aimed at ensuring equal status for women.
\end{abstract}

\section{TABLE OF CONTENTS}

I. INTRODUCTION .................................. 707

II. CANADIAN WOMEN AND ACCESS

to Reproductive Health CARE $\ldots \ldots \ldots \ldots \ldots \ldots \ldots \ldots \ldots \ldots . \ldots 711$

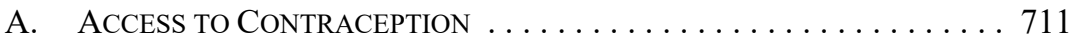

B. ACCESS TO ABORTION . ........................ 716

C. Access to Reproductive Health Care Services for CANADA's First NATIONS, METis, AND INUIT WOMEn . . . . . . . . 721

III. AUTONOMY, EQUALITY, AND ACCESS:

IMPROVIng ACCESS to RePRoductive HeALth CARE . . . . . . . . . . 722

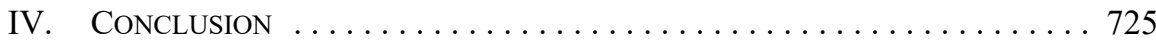

\section{INTRODUCTION}

This is an exciting time for Canadian women. We have a Prime Minister who is proud to call himself a feminist and who is working to secure women's equality. ${ }^{1}$ He has spoken on issues considered critical by many feminists, including violence against women, the earnings gap, and the need for more women in positions of power, both in public office and in private business. ${ }^{2}$ But what we have not heard much about is women's sexual and reproductive health and rights. In particular, we have heard nothing about the importance of access to sexual and reproductive health services for women's equality. Access to health care services is understood in multiple ways, but here I refer to access in an inclusive way, to mean "the opportunity to identify healthcare needs, to seek healthcare services, to reach, to obtain or

Professor, Faculty of Law, University of Alberta. Professor Nelson teaches Torts, Law \& Medicine, and Health Care Ethics \& the Law. Her research focuses on issues in health law and policy. Professor Nelson explores issues in reproductive health law and policy in her book Law, Policy and Reproductive Autonomy (Oxford: Hart, 2013).

$1 \quad$ See e.g. Alexander Panetta, "Justin Trudeau Pushes for Gender Euality at UN Women's Conference," Global News (16 March 2016), online: <globalnews.ca/news/2581600/justin-trudeau-pushes-for-genderequality-at-un-womens-conference/>; "Justin Trudeau: When I call Myself a Feminist, Twitter Explodes," The Guardian (17 March 2016), online: <https:/www.theguardian.com/world/2016/mar/ 17/justin-trudeau-feminist-twitter-explodes>. Ibid. 
use health care services and to actually have the need for services fulfilled." 3 Access to sexual and reproductive health services is an essential piece - albeit certainly not the only one — of reproductive justice, ${ }^{4}$ and its absence from public discussion about women's equal participation is notable.

Both women and men have sexual and reproductive health care needs. But the implications of a lack of ready access to sexual and reproductive health care services are far more intense for women than for men. Women's autonomy and equality - their ability to chart their own lives and have opportunities to participate fully in civic and economic life depend on their ability to obtain sexual and reproductive health care in ways that men's do not. Women's social and political circumstances are intimately connected to their ability to access sexual and reproductive health services and thereby exert some degree of control over their sexual and reproductive lives. In my view, the interrelationship between reproductive autonomy, equality, and access to sexual and reproductive health care is obvious and critically important.

The interdependency of women's sexual and reproductive health and rights and women's autonomy and equality has long been a concern for domestic and international organizations and advocacy groups seeking to promote a sexual and reproductive rights agenda. ${ }^{5}$ The work of these advocacy groups is vital, and while it has resulted in the advancement of women's sexual and reproductive rights, serious concerns persist about women's ability to access reproductive health care services. Indeed, the difficulties faced by women in some parts of the world can only be described as staggering. A few examples drawn from developing regions suffice to paint a disheartening picture. ${ }^{6}$ Approximately 225 million women in developing countries have an unmet need for modern contraception, meaning that they wish to avoid becoming pregnant and are not using an effective contraceptive method. ${ }^{7}$ Based on World Health Organization (WHO) recommendations for effective prenatal care, more than half of the 125 million women who give birth each year in developing regions receive inadequate prenatal care. ${ }^{8}$ Roughly 20 percent ( 21 million) need care for major obstetric complications but do not receive it. ${ }^{9}$ Nearly a third (33 million) of these women have

Jean-Frederic Levesque, Mark F Harris \& Grant Russell, "Patient-Centred Access to Health Care: Conceptualising Access at the Interface of Health Systems and Populations" (2013) 12:1 Int J Equity Health 1 at 8 , online: <www.equityhealthj.com/content/12/1/18>.

4 See e.g. Joan C Chrisler, "Introduction: A Global Approach to Reproductive Justice — Psychosocial and Legal Aspects and Implications" (2013) 20:1 Wm \& Mary J Women \& L 1; Rosalind P Petchesky, "Human Rights, Reproductive Health and Economic Justice: Why They are Indivisble" (2000) 8:15 Reproductive Health Matters 12.

5 Including, among others: the Alan Guttmacher Institute (Guttmacher Institute), the United Nations Family Planning Institute (UNFPA), the Center for Reproductive Rights, Planned Parenthood, and the World Health Organization (WHO).

6 The authors of the study referred to relied upon the definition of developing regions provided by the United Nations Population Division in its 2012 classification of countries. According to that report, developing regions include the Caribbean, Africa, and Asia, excluding Australia, Japan, and New Zealand. Susheela Singh, Jacqueline E Darroch \& Lori S Ashford, Adding it Up: The Costs and Benefits of Investing in Sexual and Reproductive Health, 2014 (New York: Guttmacher Institute, 2014) at 8, online: <https://www.guttmacher.org/report/adding-it-costs-and-benefits-investing-sexual-and-repro ductive-health-2014>

Ibid at 10 . Not all of the unmet need is due to inaccessibility; there are multiple causes. See e.g. John Bognaarts \& Judith Bruce, "The Causes of Unmet Need for Contraception and the Social Content of Services" (1995) 26:2 Studies in Family Planning 57.

8 Singh, Darroch \& Ashford, supra note 6 at 16. See also World Health Organization, "Standards for Maternal and Neonatal Care: Provision of Effective Antenatal Care" (WHO, 2006), online: <www.who. int/reproductivehealth/publications/maternal_perinatal_health/effective_antenatal_care.pdf $>$ Singh, Darroch \& Ashford, ibid at 4. 
newborns who need, but do not receive, care for post-delivery complications. Over a million of these women are living with HIV, more than one-third of whom are not receiving the antiretroviral medication they need to prevent transmission of the virus to their newborns and to protect their own health. ${ }^{10}$

Canadian women do not face access problems on a scale anything like that in developing regions. Sexual and reproductive health care services can be legally obtained in Canada, and in some cases are even paid for by provincial or territorial health care insurance plans. But while we have reason to believe that our access problems are not dire, in reality, we know little about their true magnitude. There is almost no Canadian data available that would provide a clear picture of how accessible reproductive health services actually are. We know that most women who live in or near a large urban centre, are educated, and are otherwise relatively "well off" can probably access the services they need, as is the case with access to health care in general. ${ }^{11}$ But what about women who are living in poverty, or are newcomers to Canada, or are otherwise marginalized? What about Canada's Aboriginal women, a group that faces intersecting disadvantages? Do these women have access to the sexual and reproductive health care services they need and want? While we lack the data that would allow us to pinpoint the extent to which Canadian women have difficulty obtaining sexual and reproductive health care, there are many signals that should lead us to raise questions about the accessibility of these health care services.

Why might access to care issues be a problem in a jurisdiction like Canada, with permissive laws and a commitment to making services available on the basis of need rather than ability to pay? One contributing factor is the absence of concrete policy around sexual and reproductive health care. Our current approach, which views sexual and reproductive health care as a comprehensive concern involving a wide array of health care needs, is a relatively new one. ${ }^{12}$ In the past, sexual and reproductive health concerns were treated as distinct categories such as maternal and child health, which were traditionally viewed as raising very different concerns from those related to sexually transmitted infection (STI) prevention. So it is not surprising that most jurisdictions, Canada included, lack a cohesive approach to the delivery of sexual and reproductive health care services. ${ }^{13}$ The result is that services and education are provided in a fragmentary, uncoordinated way. Without a policy aim or agenda on sexual and reproductive health and rights, we have no benchmarks against which to assess whether women are able to obtain the sexual and reproductive health care services they require, nor to highlight problems or devise solutions. This suggests that in order to understand and resolve access to care issues, we must first advocate for the adoption

$10 \quad$ Ibid.

11 Canadian Medical Association, "Ensuring Equitable Access to Care: Strategies for Governments, Health System Planners, and the Medical Profession: Position Statement" (Ottawa: CMA, 2013), online : $<$ https://www.cma.ca/Assets/assets-library/document/en/advocacy/PD14-04-e.pdf>.

12 An inclusive view of reproductive health was first adopted by the international community at the 1994 International Conference on Population and Development (ICPD) in Cairo, see UN, Report of the International Conference on Population and Development, Cairo, 5-13 September 1994 (New York: UN, 1995) [Cairo Report].

13 Erin Nelson, Law, Policy and Reproductive Autonomy (Oxford: Hart, 2013) at 53-54, 56-70. 
of sexual and reproductive health policy, ideally on a national basis. ${ }^{14}$ Equally important, this policy must explicitly recognize the importance of respect for reproductive autonomy.

Space does not permit the full development here of the conception of autonomy that I think we need to pursue in crafting sexual and reproductive health and rights policy. ${ }^{15}$ For the purposes of this piece, it is sufficient to note that in my view, autonomy (and reproductive autonomy specifically) requires considerable attention to context, not just the provision of a menu of options. ${ }^{16}$ It is a richer and more nuanced conception than one that suggests that the best way to respect reproductive autonomy is to provide as wide an array of options as possible and let individuals make their own choices. ${ }^{17}$ And, most importantly for the purposes of my argument here, reproductive autonomy demands a "hands on" approach by the state and its systems and institutions, as well as state support to ensure that women have meaningful choices and access to services. ${ }^{18}$ Providing meaningful access to sexual and reproductive health care is essential to ensuring women's reproductive autonomy, and must be part of any political endeavour aimed at ensuring equal status for women.

Sexual and reproductive health care includes a wide range of health care services and interventions. A basic conception of reproductive health care includes contraceptive care, abortion, pre-natal care, care during labour and delivery, post-partum care (including newborn care), assisted reproductive technology treatment, treatment and prevention of diseases of the reproductive system and organs (including endometriosis and sexually transmitted infections), and prevention of mother-to-child transmission of HIV. ${ }^{19}$ Of this inclusive list, I will focus here on two specific care types: contraception and abortion. I will also highlight the disproportionate barriers to access faced by a specific group of Canadian women: our female Aboriginal population. After providing a snapshot of actual and potential access issues in Canada, I will identify priorities for immediate government action. ${ }^{20}$

Before turning to a more detailed consideration of contraception and abortion, I want to note that both have unique histories within the context of reproductive health care, in that both were historically subject to criminal prohibitions and treated as a matter for the criminal law rather than as health care issues. ${ }^{21}$ Why then focus on these two issues, given that their treatment in law and policy might not be representative of sexual and reproductive health and rights more broadly? In part to underscore the reality that simply removing criminal restrictions around contraception and abortion does not translate into meaningful access to

14 I recognize that this is a tall order in a federal system like ours, where health policy has traditionally been viewed as a provincial responsibility. See e.g. William Lahey, "Medicare and the Law: Contours of an Evolving Relationship" in Jocelyn Downie, Timothy Caulfield \& Colleen M Flood, Canadian Health Law and Policy, 4th ed (Markham: LexisNexis Canada, 2011) 1 [Downie, Caulfield \& Flood, Health Law (2011)]. I remain optimistic, however, that there is potential for cooperation and coordination among the federal and regional governments on the health policy front, given the federal government's participation in funding the provincial and territorial health care systems.

I have written about this more fully elsewhere: see Nelson, supra note 13.

Ibid at 47-51, 56-70.

Ibid.

Ibid at $47-54$.

A useful starting point for this inquiry is the definition of reproductive health adopted by the ICPD: Cairo Report, supra note 12, art 7.2.

20 Although I do not have the space here to discuss other access issues, I want to note that contraception and abortion are not the only reproductive health services that may be difficult for Canadian women to obtain. Assisted reproductive technology (ART) treatment is another area in need of policy attention. See e.g. Nelson, supra note 13 at $80-81,117-18$. 
needed services. My aim here is not to suggest that contraception and abortion can be understood to represent all issues in sexual and reproductive health - it is to highlight some areas of persistent concern.

As will be seen below, Canada's Aboriginal women face some very specific barriers to accessing reproductive health care. It is not clear whether access to abortion and contraception are particularly challenging for this group - we do not have the requisite data to tell us whether or not this is the case. ${ }^{22}$ It is important to acknowledge that there is a risk that in discussing these issues together, I will be seen to misstate the concerns of Aboriginal women, a marginalized group for whom these issues may not be relevant or significant. I do not have a definitive answer to that concern, because, as I have noted, we lack the data that would provide the answer. As Canadian women, Aboriginal women face the same barriers to access as the rest of us. In addition, there are a host of additional sexual and reproductive health care issues that confront this particular group of women - although again, it is difficult to be precise, because we lack the data that would provide us with a clear picture of the impact these barriers to access have on Aboriginal women. And an important point I am trying to make here is that a critical first step in advancing women's ability to access services, and in turn their equality, is to acknowledge the data gap and begin to address it.

\section{Canadian Women And ACCess to Reproductive Health CARE}

\section{A. ACCESS To CONTRACEPTION}

Although most Canadian women can readily obtain contraceptive products, even those women with the knowledge and means to seek contraceptive services and products may often be unable to obtain their preferred method of contraception or the method that would be most suitable in their circumstances. ${ }^{23}$ This is the result of a pervasive but invisible barrier to access: the Canadian regulatory environment. Canada's regulatory process has left Canadian women with access to far fewer contraceptive methods than are available to their international counterparts.

The differences are substantial. A 2004 study revealed that Canadian women had access to 35 percent of contraceptive products available worldwide, and 37 percent of the available hormonal contraceptives. ${ }^{24}$ In contrast, women in the United States had access to 58 percent of all contraceptives and 59 percent of hormonal contraceptives; figures for the United Kingdom were 52 percent and 54 percent respectively. ${ }^{25}$ In the case of newer contraceptive Clinics in Canada" (2013) 38 Women's Studies Intl Forum 52 at 60 [Sethna \& Doull, "Spatial Disparities"]. The authors found that "First Nations and Métis [women] were almost three times as likely [as other study participants] to report travelling more than $100 \mathrm{~km}$ to access abortion services." The authors concluded that First Nations and Metis women faced multiple barriers to accessing abortion services.

23 Amanda Black et al, "SOGC Clinical Practice Guideline No 329: Canadian Contraceptive Consensus (Part 1 of 4)" (2015) 37:10 J Obstetrics \& Gynaecology Can S1 at S7-S9 [Black et al, "Guideline 329"]. Dianne Azzarello \& John Collins, "Canadian Access to Hormonal Contraceptive Drug Choices" (2004) 26:5 J Obstetrics \& Gynaecology Can 489 at 489.

Ibid at 495-96. 
products, the study indicated that Canadian women had access to the fewest options; only 22 percent of these products were available in Canada. ${ }^{26}$

One reason for the unavailability of these products may be the length of time it takes for them to be approved by Health Canada. The study authors noted that regulatory approval of new drugs in Canada takes approximately six months longer than the same process in the US. In the case of contraceptive products, however, the delays are far longer - Canada was two and a half years behind the US for six contraceptive products seeking regulatory approval during the period of the study. ${ }^{27}$ The authors concluded that "Canada appears to be lagging behind other countries with respect to the availability of hormonal contraceptive options. A wider choice of contraceptive options, including a variety of dosage forms, routes of administration, and chemical entities, can improve access to effective contraception." 28

It is unclear whether the data from this decade-old study remain accurate, as no follow up has been published. ${ }^{29}$ Similar concerns about the timeline for drug approval arose in the recently concluded Mifegymiso approval process, which took almost three years. ${ }^{30}$ There is considerable variation in drug approval timelines in any jurisdiction, for numerous reasons, including (as was the case with Mifegymiso) the need for the regulator to request further information from the manufacturer. The median time for drug approval in Canada is around one year, with the average time for approval being closer to $13-14$ months. ${ }^{31}$

In addition to the sometimes lengthy delays in approving contraceptive drugs, another contributing factor to the unavailability of some of these products is the continued insistence by Health Canada on recent clinical trial data as part of the approval process. Some of these products have been approved in other jurisdictions for many years. The clinical trial data is therefore older than what Health Canada will accept and there is likely no perceived benefit for a drug manufacturer to re-initiate clinical trials simply to have their already-approved drug approved in Canada, a relatively small market in global terms. ${ }^{32}$

Ibid at 496.

As of 1 January 2004: ibid at 495.

Ibid at 499.

Although a fairly recent news story suggests that not much has changed: see Adriana Barton, "It's Time to Give Canadian Women More Options When it Comes to Birth Control, Experts Say," The Globe and Mail (12 April 2015), online: <www.theglobeandmail.com/life/health-and-fitness/health/canadians-feelthe-cost-of-health-policies-limiting-access-to-birth-control/article23883108/>. See also Black et al, "Guideline 329," supra note 23 at S9.

30 Mifegymiso is a combination of mifepristone (a drug that causes the uterine lining to break down and thereby ends the pregnancy) and misoprostol (a drug that induces uterine contractions, leading to the emptying of the uterus). Health Canada, "Regulatory Decision Summary: MIFEGYMISO" (29 July 2015), online: $<$ hc-sc.gc.ca/dhp-mps/prodpharma/rds-sdr/drug-med/rds_sdr_mifegymiso_160063-eng. $\mathrm{php}>$. The summary indicates that the request for approval was filed on $\overline{14}$ November 2012 . Health Canada issued a Notice of Compliance to the manufacturer on 29 July 2015. Mifepristone has been available in several countries around the world for more than two decades: see Sophie Christin-Maitre, Philippe Bouchard \& Irving M Spitz, "Medical Termination of Pregnancy" (2000) 342:13 New Eng J Med 946 at 953.

31 Health Canada, "Therapeutic Products Directorate: Drug Submission Performance Annual Report, Fiscal Year 2015-2016" (Ottawa: Health Canada, 2016) at 18. The Annual Report indicates that median approval times (time from filing submission to approval date) have been fairly consistently around 350 days for the past five years. Average approval times are slightly higher, with the fastest average approval time being 378 days (2012-13). The averages for 2014-15 and 2015-16 were 425 and 424 days, respectively.

32 Adriana Barton, "Stringent Health Canada Requirements Restrict Access to Hormonal Implants," The Globe and Mail (12 April 2015), online: <www.theglobeandmail.com/life/health-and-fitness/health/ stringent-birth-control-requirements-keep-options-limited-for-canadians/article23882944/>. 
Perhaps owing to the regulatory issues described above, there is a critical gap in Canadian women's access to a specific subset of contraceptive products: long acting reversible contraceptive (LARC) methods. This category of contraceptive products includes intrauterine devices (IUDs) as well as implantable hormonal contraceptives that are implanted under the skin in the woman's arm. Implantable contraceptives are one of the most effective LARC methods available. ${ }^{33}$ They require no ongoing effort or attention by the women who use them, ${ }^{34}$ and they may be more palatable to women than are IUDs; at the very least, they provide an additional option. Currently, there is not a single implantable contraceptive product available in Canada. ${ }^{35}$

In raising the issue of access to newer contraceptive methods and products, it is essential to acknowledge the lack of real innovation in this sphere in the last several decades. Since the introduction of hormonal contraceptives in the 1960s, we have seen only incremental improvements - new drugs are variations on what is already available. ${ }^{36}$ Many of the newer contraceptive products are therefore not pioneering innovations with transformative potential for women's lives. Instead they are dose or delivery method modifications, and are often marketed more for their secondary benefits (such as treating acne and premenstrual pain) than for their superiority in preventing pregnancy. ${ }^{37}$ The result is that pharmaceutical companies continue to profit while women continue to wait for better options. ${ }^{38}$

In view of the lack of genuine innovation in contraceptive research and development, it is fair to ask whether the unavailability of some of these newer products is actually a problem. To be clear, my aim is not to argue that Canadian women must have access to every conceivable brand and type of contraceptive on the market. It is to raise questions about whether the limits on types and methods of contraception available in Canada are creating or contributing to problems with access. As I note above, one potentially important example is the total inaccessibility of an entire class of contraceptives in Canada: LARCs. This is a significant gap - LARCs are a class of contraceptives with very favourable efficacy and adherence rates. ${ }^{39}$ Indeed, because LARCs are highly effective and well tolerated, those involved in front line family planning services in many countries have sought to find ways

Failure rates are typically less than 1 percent. See Brooke Winner et al, "Effectiveness of Long-Acting Reversible Contraception" (2012) 366:21 New Eng J Med 1998; Anna Glasier, "Implantable Contraceptives for Women: Effectiveness, Discontinuation Rates, Return of Fertility, and Outcome of Pregnancies" (2002) 65:1 Contraception 29.

34 See e.g. American College of Obstetricians and Gynecologists, "Practice Bulletin Number 121: LongActing Reversible Contraception: Implants and Intrauterine Devices"(2011), online: $<$ https://www.acog. org/-/media/Practice-Bulletins/Committee-on-Practice-Bulletins----Gynecology/Public/pb121.pdf` [ACOG, "Practice Bulletin"]; Megan L Kavanaugh et al, "Characteristics of Women in the United States Who Use Long-Acting Reversible Contraceptive Methods" (2011) 117:6 Obstetrics \& Gynecology 1349; Barton, supra note 32.

35 Barton, ibid; Black et al, "Guideline 329," supra note 23 at S9.

36 Heather Boonstra et al, "The 'Boom and Bust Phenomenon': The Hopes, Dreams, and Broken Promises of the Contraceptive Revolution" (2000) 61:1 Contraception 9; Carl Djerassi, "The Bitter Pill" (1989) 245:4916 Science 356; Jerome F Strauss III \& Michael Kafrissen, "Waiting for the Second Coming" (2004) 432:7013 Nature 43; Michael JK Harper, "In Search of a Second Contraceptive Revolution" (2005) 3:2 Sexuality Reproduction \& Menopause 59. Elizabeth Siegel Watkins, "How the Pill Became a Lifestyle Drug: The Pharmaceutical Industry and Birth Control in the United States Since 1960" (2012) 102:8 American J Public Health 1462. Ibid.

39 Megan L Kavanaugh et al, "Meeting the Contraceptive Needs of Teens and Young Adults: YouthFriendly and Long-Acting Reversible Contraceptive Services in U.S. Family Planning Facilities" (2013) 52:3 J Adolescent Health 284 [Kavanaugh et al, "Contraceptive Needs"]; ACOG "Practice Bulletin," supra note 34 . 
to promote increased use of these products. ${ }^{40}$ Given the persistently high rates of unintended pregnancy seen worldwide, it seems clear that we need to do more to ensure that women have access to contraceptive options that are effective and that they will use consistently. ${ }^{41}$

Like the current regulatory process, the structure of Canada's health care system itself creates some barriers to access that could be easily addressed to improve women's access to contraception. The Canadian health care scheme, known colloquially as "medicare," is in reality 13 unique systems, in that each province and territory is responsible for delivering medical care to its residents and for devising a system through which to do so. ${ }^{42}$ The federal government also has a role in health care service delivery, based on its responsibility to provide health care to specific groups of people: First Nations and Inuit people, members of the Canadian Forces and veterans, inmates in Federal penitentiaries, and refugee claimants. ${ }^{43}$ Provincial and territorial health care insurance plans are centred on the provision of hospital and physician services, meaning that products or services received by outpatients and provided by health care professionals other than physicians are often not covered by the public system. ${ }^{44}$

In theory, the system provides universal and comprehensive coverage to meet the medical needs of Canadians. ${ }^{45}$ But the focus on physician services and in-hospital care leaves an evergrowing and increasingly important list of services out of the medicare basket. ${ }^{46}$ In terms of contraceptives specifically, some products and services are covered, but many are outside of the scope of coverage. The most permanent forms of birth control, such as sterilization procedures (tubal ligation and vasectomy), are the most fully covered, owing to their status as physician-provided, medically necessary services. ${ }^{47}$ Prescription medications are not comprehensively covered by most provincial health care insurance plans. ${ }^{48}$ This means that the costs of birth control pill prescriptions are typically borne by individual women, unless they have coverage under a private supplemental health insurance plan. Provincial plans do not provide non-prescription contraceptives (such as condoms, spermicides, contraceptive sponges, and emergency contraception). The cost of an IUD is not covered by most provincial health care plans, but the physician office visits required for prescription, ${ }^{49}$

Kavanaugh et al, ibid; ACOG "Practice Bulletin," ibid.

Almost half (45 percent) of pregnancies in the US are unintended: Lawrence B Finer \& Mia R Zolna, "Declines in Unintended Pregnancy in the United States, 2008-2011"(2016) 374:9 New Eng J Med 843. Canada does not track data of the prevalence of unintended pregnancies, nor do we collect reliable data on the use of contraceptives or abortion rates. See Black et al, "Guideline 329," supra note 23 at S2. Colleen M Flood, "The Structure and Dynamics of Canada's Health Care System" in Jocelyn Downie \& Timothy Caulfield, eds, Canadian Health Law and Policy (Toronto: Butterworths, 1999) 5 at 11-24; Lahey, supra note 14.

See Flood, ibid.

Ibid. See also Nelson, supra note 13 at $85-86$

Flood, supra note 42.

See generally Roy J Romanow, "Building on Values: The Future of Medicare in Canada - Final Report" (Ottawa: Commission on the Future of Health Care in Canada, November 2002).

These procedures are covered in most provincial and territorial health care insurance plans.

Lahey, supra note 14 at 26. Some provinces have "pharmacare" programs that provide some prescription drug coverage: see e.g. British Columbia, Ministry of Health, "Pharmacare for B.C. Residents," online: <www2.gov.bc.ca/gov/content/health/health-drug-coverage/pharmacare-for-bcresidents>; Manitoba Health, Seniors and Active Living, "Manitoba Pharmacare Program," online: $<$ www.gov.mb.ca/health/pharmacare/index.html $>$.

The cost of an IUD can range from $\$ 90$ to $\$ 400$. This cost is the responsibility of the patient herself. See G Menard, M Pineau \& S Laplante, "A Cost-Minimization Analysis Comparing Mirena ${ }^{\circledR}$ with Oral Contraceptives" (2001) 4:2 Value in Health 165; Sheila Wijayasinghe, "Ask a Health Expert: Should I Use an IUD for Birth Control?" The Globe and Mail (8 March 2011), online: <www.theglobe andmail.com/life/health-and-fitness/ask-a-health-expert/should-i-use-an-iud-for-birth-control/ article569781/>. 
insertion, and removal of the device are covered (as they are insured physician services). Various contraceptives - both prescription and non-prescription — can be obtained free of charge or at a subsidized rate in some sexual health clinics and some university health service clinics. ${ }^{50}$ It is clear that coverage for contraceptive products and services is far from comprehensive; the conclusion that access would be improved with more inclusive coverage seems inescapable.

In addition to the gaps in funding for and availability of contraceptives, provider conscientious objection poses yet another potential barrier to access for women seeking contraceptive services. Provider objection can make access difficult, even impossible, especially for women who have limited choice in where to seek services, including those with low incomes and those who do not live in urban centres. ${ }^{51}$ Though we know little about the frequency with which conscientious objection poses a problem for contraceptive access, anecdotal accounts show that it does occur. ${ }^{52}$ It is not only physicians who may object - a growing number of pharmacists assert a right to object to the provision of services (and to the provision of referrals to other providers who will furnish the requested service) that they find morally or religiously offensive. ${ }^{53}$

An important consideration in this context is the scope of permissible objection, which turns on what it means to "participate" in the provision of contraceptive products and services. ${ }^{54}$ Some providers insist that their religious or moral values require not only that they decline to perform or prescribe an objectionable procedure or treatment, but that they must also refrain from referring their patient to a non-objecting provider. ${ }^{55}$ The more inclusive the definition of participation, the more significant the barrier to access created by conscientious objection. In the absence of clearly articulated rules from legislatures and professional regulatory bodies that clarify what providers can and cannot refuse to do on the basis of conscience, women remain vulnerable to providers who prioritize their religious or moral views over the needs of their patients. This is an issue in the context of access to abortion as well.

Amanda Black et al, "SOGC Clinical Practice Guideline No 143: Canadian Contraception Consensus, Part 1 of 3" (2004) 26:2 J Obstetrics \& Gynaecology Can 143 at 152.

51 Jayne Lucke et al, "Unintended Pregnancies: Reducing Rates by Improving Access to Contraception" (2011) 40:11 Austl Family Physician 849; Tania Khan \& Megan Arvad McCoy, "Access to Contraception" (2005) 6:3 Geo J Gender \& L 785; Holly Teliska, "Obstacles to Access: How Pharmacist Refusal Clauses Undermine the Basic Health Care Needs of Rural and Low-Income Women" (2005) 20:1 Berkeley J Gender L \& Just 229.

52 Mike Mastromatteo, "Alberta Pharmacist Wins Concessions in Right-to-Refuse Case," The Interim (31 December 2003), online: <www.theinterim.com/issues/alberta-pharmacist-wins-concessions-in-right-torefuse-case/>; Barbara Sibbald, "Nonprescription Status for Emergency Contraception" (2005) 172:7 CMAJ 861; "Lloyds Pharmacy Probe Over Pill Refusal in Sheffield," BBC News (10 March 2010), online: <news.bbc.co.uk/2/hi/uk news/england/south yorkshire/8557816.stm>.

53 Mastromatteo, ibid; Allison Grady, "Legal Protection for Conscientious Objection by Health Professionals" (2006) 8:5 Virtual Mentor 327.

$54 \quad$ See Bernard M Dickens, "The Right to Conscience" in Rebecca J Cook, Joanna N Erdman \& Bernard M Dickens, eds, Abortion Law in Transnational Perspective: Cases and Controversies (Philadelphia: University of Pennsylvania Press, 2014) 210.

55 Ryan E Lawrence \& Farr A Curlin, "Physicians' Beliefs About Conscience in Medicine: A National Survey" (2009) 84:9 Academic Medicine 1276. 


\section{B. ACCess to Abortion}

Since 1988, Canada has had no criminal laws prohibiting abortion. ${ }^{56}$ Instead, regulation of, and access to, abortion services is accomplished by a combination of health care professional guidelines, hospital policies, and provincial policies relating to access to, and public funding for, abortion services. ${ }^{57}$ As a result, abortion services are inconsistently available across Canada.

A recent survey of Canadian abortion services suggests that the uneven accessibility is even more profound than many feared. The survey found 94 facilities offering abortion services in Canada, nearly half (46) of which are located in Quebec. ${ }^{58}$ In British Columbia, there are eight centres located in rural areas of the province and another eight in urban centres. ${ }^{59}$ In both Quebec and British Columbia, the clinics are roughly equally distributed among urban and rural locations, and throughout the province as a whole. The remaining 32 facilities in Canada are distributed as follows: Ontario has 16 facilities, the three Prairie provinces share eight facilities, there are four in the Atlantic provinces, and another four in the Territories. ${ }^{60}$ The vast majority of abortion facilities in provinces other than Quebec and British Columbia are located in urban centres, even though significant numbers of women of reproductive age (15 to 44 ) live outside of these areas. For example, in the Prairies, abortion facilities are found only in "census metropolitan areas" (CMAs) and 40 percent of women of reproductive age live somewhere other than a CMA with a facility. ${ }^{61}$ In Ontario, 35 percent of women aged 15 to 44 live outside of a CMA with a facility, and no abortion facilities are located in rural areas. ${ }^{62}$

Depending upon how far away from a CMA with abortion services a woman lives, the travel distance may be manageable. But many must travel significant distances to access abortion services. ${ }^{63}$ For example, women who live in Fort McMurray or Grande Prairie, Alberta appear to have to travel to Edmonton (roughly 4 and a half hours by car) to get to the nearest facility. ${ }^{64}$ Women living in Medicine Hat, Alberta, are $266 \mathrm{~km}$ from Calgary, where the nearest facility is located. In Ontario, women living in Thunder Bay have limited access to surgical abortion services at a local hospital, and the nearest clinics are in Winnipeg (700 $\mathrm{km}$ away) or Toronto (1,400 km away). Women in Northeastern Ontario communities

For a more detailed discussion, see Nelson, supra note 13 at 116-19. Ibid at 137-39.

Wendy V Norman et al, "Abortion Health Services in Canada: Results of a 2012 Survey" (2016) 62:4 Can Family Physician e209; Lauren Vogel, "Abortion Access Grim in English Canada” (2015) 187:1 CMAJ 17.

Norman et al, ibid at e212-13.

Ibid.

Ibid at e212. A "census metropolitan area" is defined by Statistics Canada as consisting of "one or more neighbouring municipalities situated around a core" and having a minimum total population of 100,000 people, of which at least half live in the core. Statistics Canada, "Census Dictionary," Online Catalogue no 98-301-XWE, online: <https://www12.statcan.gc.ca/census-recensement/2011/ref/dict/geo009eng.cfm $>$.

Norman et al, supra note 58 .

See Sethna \& Doull, "Spatial Disparities," supra note 22.

Vincent McDermott, "Travel, Stress and Expenses Hurdles for Fort McMurray Women Seeking Abortions," Fort McMurray Today (9 March 2015), online: <www.fortmcmurraytoday.com/2015/03/09/ travel-stress-and-expenses-hurdles-for-fort-mcmurray-women-seeking-abortions $>$. It is my understanding that there may be physicians who are willing to provide abortion services in local hospitals in some other Alberta cities. However, these providers do not advertise widely and even women who live in those cities may not be aware of the availability of local services. 
(including Timmins, with a population of over 300,000) must travel for abortion services, most of which are located in the Toronto area, roughly $550 \mathrm{~km}$ away. Although the precise implications of the distribution of abortion clinics are difficult to pin down, the uneven distribution of abortion facilities certainly has the potential to make access to abortion services difficult for women who live outside of Canada's major cities. ${ }^{65}$

In addition to the disparate distribution of abortion facilities, the type of facilities available in a given region can affect a woman's ability to obtain abortion services. Three provinces and all three territories lack non-hospital abortion facilities. Though abortions are available in some hospitals in these areas, the number of Canadian hospitals that provide abortion services is surprisingly low, and appears to be declining. A 2003 report by the Canadian Abortion Rights Action League noted that only 17.8 percent of Canadian hospitals performed abortion services, ${ }^{66}$ while a similar report issued by Canadians For Choice in 2006 puts the figure at 15.9 percent. ${ }^{67}$ This data is now out of date, but it is nevertheless worth emphasizing the exceptionally low numbers of hospitals providing abortion services. It is possible that participation has increased since 2006, but even a significant improvement (for example, 10 percent) would still mean that only a quarter of Canadian hospitals provide abortion services.

Though Canada prides itself on having a universal, portable public health care system, abortion services have typically been treated differently than other insured services. Funding for abortion services is determined by provincial policy, and there is significant variation across the country. Although most Canadian provinces have freestanding abortion clinics, one such province (New Brunswick) provides coverage only for in-hospital abortion procedures. ${ }^{68}$ Another example: until 2015, abortion services were excluded from the interprovincial reciprocal billing agreement. ${ }^{69}$ Under the terms of the agreement, Canadians who obtain medically necessary health care services outside of their home province do not have to pay for the services themselves. Instead, the provider can bill his or her provincial health care insurance plan for the service; the province in turn can recover the amount paid from the patient's home province. The interprovincial agreement that makes this possible has been in place since 1988, but until June 2015, abortion services were excluded from the agreement. ${ }^{70}$ Abortion was not the only physician service excluded from interprovincial reciprocal billing, but abortion services are typically required in a far more time sensitive way (and probably more frequently by women temporarily living outside of their home

$65 \quad$ Norman et al, supra note 58

66 Canadian Abortion Rights Action League, Protecting Abortion Rights in Canada: A Special Report to Celebrate the 15th Anniversary of the Decriminalization of Abortion (Ottawa: CARAL, 2003); Christabelle Sethna \& Marion Doull, "Far From Home? A Pilot Study Tracking Women's Journeys to a Canadian Abortion Clinic" (2007) 27:8 J Obstetrics \& Gynaecology Can 640.

67 Jessica Shaw, Reality Check: A Close Look at Accessing Abortion Services in Canadian Hospitals (Ottawa: Canadians for Choice, 2006).

68 British Columbia, Alberta, Manitoba, Ontario, Quebec, and Newfoundland all have freestanding abortion clinics and provide public funding for clinic abortions. New Brunswick has a clinic but will not cover the cost of clinic abortions. Saskatchewan does not have a clinic but will pay for abortion procedures at clinics in Alberta.

69 Canadian Institute for Health Information, "Have Health Card, Will Travel: Out-of-Province/-Territory Patients" (CIHI, March 2010), online: <https://secure.cihi.ca/free_products/out_of_province_aib_ 201003 e.pdf $>$.

70 Ontario, Health Services Branch, "Reciprocal Billing of Abortion Services," INFO Bulletin No NA65, online: <www.health.gov.on.ca/en/pro/programs/ohip/bulletins/na_65/na_65.pdf>. 
province, such as university students) than almost any of the other excluded services. ${ }^{71}$ The inability to obtain publicly funded abortion services created a potentially significant constraint on access for women temporarily living away from their home province, or those who lived in an area where the nearest abortion provider is in a different province and who did not have the means to pay for the cost of the procedure. While the change to include abortion services is a step in the right direction, the victory is partial, in that only abortion services provided in a hospital are covered and, as noted earlier, the vast majority of Canadian hospitals do not offer abortion services.

As with contraceptive products, the regulatory environment plays a role in determining how accessible abortion services are. There is a new option on the horizon that has significant potential to improve access to abortion in Canada: medication abortion using Mifegymiso. Because medication abortion does not require special facilities or equipment, the potential access gains are especially important for women who live in communities where there are no local abortion services, as is the case in many parts of Canada. ${ }^{72}$

In many jurisdictions, medication abortion has been readily available for over a decade (and in some cases, much longer).$^{73}$ As noted earlier, mifepristone (the only drug actually indicated for pregnancy termination) was approved in Canada in 2015. ${ }^{74}$ Even before Mifegymiso (the name under which the drug combination will be marketed) became available ${ }^{75}$ substantial concerns were raised as to how accessible the drug will be. Several restrictions have been placed on the availability of Mifegymiso. Prescribing and dispensing is limited to physicians, meaning that physicians will have to stock the drug in their offices. ${ }^{76}$ Nurse practitioners, midwives, and pharmacists will not be permitted to prescribe or dispense the drug. ${ }^{77}$ Physicians will have to participate in a specific training program before they will be permitted to dispense Mifegymiso. ${ }^{78}$ Women seeking to use Mifegymiso will be required to have an ultrasound to confirm gestational age and rule out ectopic pregnancy. ${ }^{79}$ The prescription time frame for Mifegymiso is limited to the first 49 days (seven weeks) of pregnancy, although the WHO has said it is safe and effective up to 63 days (nine weeks). ${ }^{80}$

71 Some examples of excluded services are as follows: cosmetic surgery; sex-reassignment surgery; surgery to reverse a sterilization procedure; routine health examinations; assisted reproduction services; genetic screening or testing; lithotripsy for gall bladder stones and services requested by a third party (such as employment-related medical examination). See Alberta Health, Hospital Reciprocal Claims Guide, (Government of Alberta, June 2016), online: <www.health.alberta.ca/documents/Hospital-ReciprocalClaims-Guide.pdf>.

$72 \quad$ Norman et al, supra note 58 and accompanying text.

73 The first jurisdiction to approve mifepristone was France, in 1988: Christin-Maitre, Bouchard \& Spitz, supra note 30 at 953 .

74 Health Canada, "Mifegymiso: Summary Basis of Decision" (Health Canada, 11 January 2016), online: $<$ hc-sc.gc.ca/dhp-mps/prodpharma/sbd-smd/drug-med/sbd-smd-2016-mifegymiso-160063-eng.php> ["Summary Basis of Decision"].

75 Kelly Grant, "Long-Awaited Abortion Pill Mifegymiso Makes Canadian Debut," The Globe and Mail (20 January 2017), online: <www.theglobeandmail.com/news/national/long-awaited-abortion-pillmifegymiso-rolls-out-in-canada/article33695167/>.

76 "Summary Basis of Decision," supra note 74.

77 Ibid. See also Grace Lisa Scott, "A New Abortion Pill Will be Available in Canada Soon, But it's Not a Simple Solution to Access,"VICE Magazine (21 January 2016), online: <www.vice.com/en ca/read/ new-abortion-pill-not-a-simple-solution-to-abortion-access-in-canada $>$.

"Summary Basis of Decision," supra note 74.

Ibid.

World Health Organization, Safe Abortion: Technical and Policy Guidance for Health Systems, 2nd ed (Geneva: WHO, 2012) at 38, online: <apps.who.int/iris/bitstream/10665/70914/1/9789241548434 eng.pdf $>$. The US FDA has recently approved a revised label that permits the use of mifepristone up to 70 days since the woman's last menstrual period, see US, Food and Drug Administration, "Mifeprix 
These limitations, together with the cost of the medication (estimated to be approximately \$270), do not bode well for increased access to abortion for Canadian women. ${ }^{81}$

Mifepristone has been used safely and effectively in at least one country for nearly 30 years. It has enormous potential to improve access to abortion, but some aspects of the protocol mandated by Health Canada (and agreed to by the Canadian distributor) actually seem designed to limit rather than enhance access. And though Health Canada insists that the restrictive rules are required for safe administration of Mifegymiso ${ }^{82}$ it is questionable whether this is a legitimate rationale. One medical expert, Dr. Wendy Norman, has explained that there is no therapeutic justification for some of the restrictions imposed on Mifegymiso, including the requirement for physician dispensing. ${ }^{83}$ Norman notes that she has spoken to many physicians who say that they will not offer Mifegymiso because they lack the administrative structure within their offices to dispense the drug. ${ }^{84}$

The requirement for routine pre-prescription ultrasound may also be unnecessary. According to the Royal College of Obstetricians and Gynaecologists in the UK (RCOG), there is no direct evidence justifying routine pre-abortion ultrasound on the basis of safety or efficacy. ${ }^{85}$ The RCOG notes that pre-abortion ultrasound is not routine in France, and that medical abortion can be safely provided in "resource-poor settings which do not have access to routine ultrasound." 86 A recent US study evaluating the need for routine ultrasound before abortion concluded that relying on the date of the woman's last menstrual period plus a physical examination resulted in only a small number of women being accepted for medication abortion outside of the permitted 63 day time frame. ${ }^{87}$ Based on the evidence, the RCOG has concluded that routine pre-procedure ultrasound is not indicated, absent some reason to be concerned about dates or about the physician's ability to examine the woman. ${ }^{88}$ The RCOG further notes that requiring routine ultrasound "adds to the costs of the service and, in some places, limits the number of assessment appointments that can be made available." 89

If a regulatory body in the UK could conclude five years ago that routine pre-abortion ultrasound is unnecessary, it is fair to ask why ultrasound will be mandatory for Canadian women seeking to use Mifegymiso. If ultrasound is actually necessary for health and safety

(mifepristone) Information," online: <www.fda.gov/Drugs/DrugSafety/PostmarketDrugSafety InformationforPatientsandProviders/ucm111323.htm $>$.

Scott, supra note 77. It is unclear at this stage whether the cost of Mifegymiso will be covered by provincial health care insurance plans.

See e.g. Sharon Kirkey, "Home Abortion Pill About to Hit Market in Canada, but has Already Garnered Criticism," National Post (19 April 2016), online: <news.nationalpost.com/news/canada/0420-naabortion>.

Ibid.

Ibid. The distributor has applied to Health Canada asking that pharmacists be permitted to dispense the drug and requesting an extension to the prescription time frame to 63 days: Grant, supra note 75 .

Royal College of Obstetricians and Gynaecologists, The Care of Women Requesting Induced Abortion: Evidence-Based Clinical Guideline Number 7 (London, UK: RCOG Press, November 2011) at 52 [RCOG, The Care of Women]. Ibid.

See H Bracken et al, "Alternatives to Routine Ultrasound for Eligibility Assessment Prior to Early Termination of Pregnancy with Mifepristone-Misoprostol" (2011) 118:1 British J Obstetrics \& Gynaecology 17.

RCOG, The Care of Women, supra note 85 at 52. Ibid. 
reasons, then it should be mandatory. But if not, and if access can be improved by removing this requirement, it should be removed.

Both physician-only dispensing and routine pre-abortion ultrasound will very likely have the practical effect of making Mifegymiso available in abortion clinics rather than in physician's offices. This will all but defeat the drug's potential to improve women's ability to access abortion services.

The restrictions around Mifegymiso are particularly worrying given the US experience with mifepristone. The drug has been available in the US for 16 years ${ }^{90}$ and its potential reach has been limited in many ways. Lawmakers in some states have restricted access by creating laws that require physicians prescribing mifepristone to be in the same room as the patient they are prescribing it for, and requiring physicians to prescribe mifepristone based on an outdated FDA treatment regimen that requires an unnecessarily high dose and that requires more follow-up office visits than newer regimes. ${ }^{91}$ Abortion law and policy in the US and Canada are very different, and I do not wish suggest that Canada's experience with medication abortion will mirror that of the US. ${ }^{92}$ Rather, I am advocating vigilance in watching for restrictions on access to medication abortion and for continued insistence that any such restrictions be justified on the basis of health and safety so that we do not miss out on the promise of increased access to abortion that Mifegymiso offers.

As in the case of contraceptive services, provider conscientious objection is another potentially significant barrier to access faced by women seeking abortion services. In the absence of law specifying the scope of permissible objection, Canadian women can encounter physicians who not only refuse to perform abortions or prescribe a medication abortion regimen, but who also insist that their "right" to conscientiously object extends to a refusal to refer women to willing providers. ${ }^{93}$ It is impossible to know how frequently women's ability to access abortion is frustrated by provider refusal, as there is no reliable way to track such data, but it is clear from anecdotal reports that this does occur. ${ }^{94}$

Heather D Boonstra, "Mifepristone in the United States: Status and Future" (2002) 5:3 Guttmacher Policy Rev 4.

Molly Redden, "FDA Approves New Abortion Drug Label in Win for Public Health Advocates," The Guardian (30 March 2016), online: <www.theguardian.com/world/2016/mar/30/fda-approves-newabortion-drug-labeling-reproductive-rights $>$.

For more detailed information on US law and policy, see e.g. Alan Guttmacher Institute, “An Overview of Abortion Laws" (1 August 2016), online: <www.guttmacher.org/state-policy/explore/overviewabortion-laws $>$. See also Nelson, supra note 13 at 119-26.

Dickens, supra note 54 at 229. The College of Physicians and Surgeons of Ontario has recently adopted a rule that will require objecting providers to refer patients to non-objecting colleagues or face possible disciplinary action. A group called the Christian Medical and Dental Society of Canada has applied to the Ontario Superior Court for a declaration that the College's policy infringes the constitutional rights of objecting providers: see Lauren Pelley, “Christian Doctors' Group Says New College Policy Infringes on Freedom of Conscience," The Toronto Star (24 March 2015), online: <https://www.thestar.com/ life/health_wellness/2015/03/24/christian-doctors-group-says-new-college-policy-infringes-on-freedomof-conscience.html>.

Nelson, supra note 13 at 149-50. 


\section{AcCess to Reproductive Health Care Services for CANADA's First Nations, Metis, ANd InUit WoMEN}

As Canadian women, Canada's Aboriginal women face the same barriers to accessing sexual and reproductive health care that all Canadian women face. As explained above, we do not have the data we need to know for certain whether contraception and abortion are more or less accessible to Aboriginal than non-Aboriginal women. ${ }^{95}$ In fact, we lack data that would allow any concrete conclusions around the accessibility of sexual and reproductive health services to Canada's Aboriginal women. But we do know that in addition to the above-described concerns, Canada's First Nations, Metis, and Inuit women experience a number of further difficulties relative to Canada's non-Aboriginal population. Though many of these issues are persistent and familiar as problems facing Canada's Aboriginal population, ${ }^{96}$ they have less well-known implications for sexual and reproductive health and bear brief consideration here.

Inadequate and unsafe housing is common in many First Nations communities, leading to significant overcrowding and public health concerns. ${ }^{97}$ These communities often lack basic sanitation and infrastructure. The most recent statistical data on this point indicate that close to a third of First Nations people living on-reserve live in crowded homes, meaning that there is more than one person per room living in the home. ${ }^{98}$ In the non-Aboriginal population, by contrast, approximately 4 percent of Canadians live in crowded homes. In addition, over 40 percent of First Nations persons living on-reserve live in homes requiring major repairs. ${ }^{99} \mathrm{Of}$ those who live off-reserve, 15 percent live in such circumstances. ${ }^{100}$ Among non-Aboriginal Canadians, 6.8 percent live in homes requiring major repairs. ${ }^{101}$ Food insecurity is much higher among Aboriginal than non-Aboriginal Canadians. ${ }^{102}$ On First Nations reserves, food and safe drinking water are often inaccessible, which is of particular concern to pregnant and breast-feeding women and young children. ${ }^{103}$

In terms of access to reproductive health care, the picture is equally grim. A recent Society of Obstetricians and Gynaecologists of Canada policy statement on maternity services available to Aboriginal Canadians living on-reserve describes the human resources situation

See Sethna \& Doull, "Spatial Disparities," supra note 22 (barriers to access faced by some Aboriginal Canadian women seeking abortion services).

Laura Eggertson, "Election 2015: Closing the Aboriginal Health Gap" (2015) 187:16 CMAJ E469; Laura Eggertson, "Despite Federal Promises, First Nations' Water Problems Persist" (2008) 178:8 CMAJ 985. 97 See Statistics Canada, "Aboriginal Peoples: Fact Sheet for Canada" by Karen Kelly-Scott \& Kristina $<$ www.statcan.gc.ca/pub/89-656-x/89-656-x2015001-eng.pdf>.

$98 \quad$ Ibid at 4

$99 \quad$ Ibid at 5

100 Ibid.

101 Ibid.

102 According to a 2009 report, "[r]ates of food insecurity for First Nations populations living on-reserve vary from $21 \%$ to $83 \%$ ": Kelly McShane, Janet Smylie \& Paul Adomako, "Health of First Nations, Inuit, and Métis Children in Canada" in Janet Smylie \& Paul Adomako, eds, Indigenous Children's Health Report: Health Assessment in Action (Toronto: Keenan Research Centre, 2009) at 24, online: <caid.ca/ IndChiHeaRep2009.pdf>.

103 See e.g. Constance MacIntosh, "Indigenous Peoples and Health Law and Policy: Responsibilities and Obligations" in Downie, Caulfield \& Flood, Health Law (2011), supra note 14, 575 at 582; Jessica Yee et al, "SOGC Joint Policy Statement No 259: Sexual and Reproductive Health, Rights, and Realities and Access to Services for First Nations, Inuit, and Métis in Canada" (2011) 33:6 J Obstetrics \& Gynaecology Can 633 at 634 . 
as being in a "state of crisis." 104 Prenatal care can be particularly difficult to access for women living in remote locations where physicians and other health care personnel are scarce. ${ }^{105}$ In addition to having limited access to health care during pregnancy, Aboriginal women who live in remote areas have to leave their communities for part of their pregnancy (up to a month in some cases) to deliver. ${ }^{106}$

Not only do many Aboriginal women have difficulty accessing health care services, they also suffer from more reproductive health-related ailments than their non-Aboriginal counterparts. Aboriginal women tend to have higher rates of STIs; these infections can contribute to infertility. ${ }^{107}$ Obesity rates are higher among Aboriginal women, leading to conditions that can make conception more difficult. ${ }^{108}$ Aboriginal mothers tend to be younger than non-Aboriginal mothers, they tend to have more children, ${ }^{109}$ and their babies have higher birth weights, which can lead to complications in labour and delivery. ${ }^{110}$

Based on these reproductive health-related concerns, it should come as no surprise that estimates suggest that Aboriginal women have worse birth outcomes compared to nonAboriginal Canadian women. Stillbirths and perinatal deaths are much higher (roughly double) for Aboriginal women than for non-Aboriginal Canadian women. ${ }^{11}$ Aboriginal women also seem to be at roughly double the risk of maternal morbidity and mortality. ${ }^{112}$ Although we lack reliable data, ${ }^{113}$ it seems clear that Canada's Aboriginal women confront significantly more reproductive health concerns and face a marked disparity in access to needed medical care compared with non-Aboriginal Canadian women.

\section{Autonomy, Equality, And ACCESs: IMPROVING ACCESS TO REPRODUCTIVE HEALTH CARE}

Canada prides itself on being a nation that respects individual autonomy and rights, especially in the context of health care decision-making. Canadians also place a high value on substantive equality. And yet, as the foregoing discussion makes clear, there are many reasons to conclude that Canadian women often find it difficult to access needed reproductive health care — health care that is fundamental to their autonomy and equality.

\section{$104 \quad$ Yee et al, ibid at 634}

105 Ibid.

Marie Chamberlain \& Kate Barclay, "Psychosocial Costs of Transferring Indigenous Women From Their Community for Birth" (2000) 16:2 Midwifery 116 at 117; Vicki Van Wagner et al, "Reclaiming Birth, Health, and Community: Midwifery in the Inuit Villages of Nunavik, Canada" (2007) 52:4 J Midwifery \& Women's Health 384.

$107 \quad$ Yee et al, supra note 103 at 634.

108 Ibid.

109 See e.g. Statistics Canada, "Women in Canada: A Gender-Based Statistical Report — First Nations, Métis and Inuit Women,” by Paula Arriagada, Catalogue no 89-503-X (Ottawa: Minister of Industry, 3 February 2016) at 4, online: $<$ www.statcan.gc.ca/access_acces/alternative_alternatif.action? $1=$ eng\&loc $=/$ pub/89-503-x/2015001/article/14313-eng.pdf $>$.

$110 \quad$ Yee et al, supra note 103 at 634.

111 Barbara SE Verstraeten et al, "Canada's Pregnancy-Related Mortality Rates: Doing Well but Room for Improvement" (2015) 38:1 Clinical \& Investigative Medicine E15; McShane, Smylie \& Adomako, supra note 102 at 30; Prakesh S Shah et al, "Pregnancy and Neonatal Outcomes of Aboriginal Women: A Systematic Review and Meta-Analysis" (2011) 21:1 Women's Health Issues 28; Zhong-Cheng Luo et al, "Birth Outcomes in the Inuit-Inhabited Areas of Canada" (2010) 182:3 CMAJ 235.

112 Canadian Public Health Association, “Overview: Healthier Mothers and Babies," online: <www.cpha.ca/ en/programs/history/achievements/06-hmb/overview.aspx>.

113 See Yee et al, supra note 103; Verstraeten et al, supra note 111; Shah et al, supra note 111; Luo et al, supra note 111. 
As I stated earlier, in my view, the connections between reproductive autonomy, equality, and access to sexual and reproductive health care are clear and have critical implications. But I want to distinguish my approach to reproductive autonomy from the prevalent view that this means that the state must stay out of individuals' reproductive business. ${ }^{114}$ Our conception of autonomy does not have to be a libertarian conception. My argument is that meaningful autonomy requires a "hands on" state, because a libertarian approach can only safeguard the autonomy of the relatively privileged. ${ }^{115}$

An essential step in improving access to reproductive health care is the development and implementation of a policy strategy that prioritizes reproductive autonomy. Even before we accomplish that aim, however, there is much that can be done to improve access to reproductive health care services. Below, I outline a few examples of straightforward, concrete priorities for government action, including steps that Canadian governments can and should take without delay.

First, data collection must be made a priority. It is not possible to overstate the importance of accurate and reliable data. We cannot solve access problems until we understand how (in)accessible reproductive health care services are, and can pinpoint where (and for whom) access is a problem. There are numerous examples of areas in which we lack data about women's ability to obtain the sexual and reproductive health care they need. We do not know the number of unintended pregnancies in Canada or the total number of pregnancies that end in abortion. ${ }^{116}$ We lack data on women's contraceptive preferences and their ability to obtain their preferred methods of contraception. ${ }^{117}$ We do not know how often women have difficulty accessing abortion services or the reasons for the difficulty. We have no data on wait times for abortion services. Although we know that rates of maternal mortality and stillbirth are higher in Canada's Aboriginal population, we lack reliable and accurate numbers to indicate precisely how much higher these risks are. ${ }^{118}$

The above-cited study showing that Canadian women have access to far fewer contraceptive options than women in many other jurisdictions is 12 years old; the data it relies on is even older. It is possible that the situation has improved since that study was conducted, but equally possible that it has not. Maybe the situation is even worse now. In terms of information about abortion access, it is not easy to discover where in Canada abortion services are available. Though there are a few Canadian advocacy organizations that endeavour to give us a sense of the accessibility of abortion, these organizations have no stable funding and have difficulty offering services and education on a continuous basis. The lists of providers that they compile are not identical and in many cases are incomplete or inaccurate. Sometimes the organizations or agencies merge or are reinvented, and data are

114 See e.g. John A Robertson, Children of Choice: Freedom and the New Reproductive Technologies (Princeton: Princeton University Press, 1994); Ronald Dworkin, Life's Dominion: An Argument About Abortion, Euthanasia, and Individual Freedom (New York: Vintage Books, 1994); John Harris, "Rights and Reproductive Choice" in John Harris \& Søren Holm, eds, The Future of Human Reproduction: Ethics, Choice, and Regulation (Oxford: Clarendon Press, 1998) 5; Julian Savulescu, "Sex Selection: The Case For" (1999) 171:7 Medical J Austl 373.

Nelson, supra note 13 at 56-70.

See note 123 , below.

Black et al, "Guideline 329," supra note 23 at S9.

See Yee et al, supra note 103; Vestraeten et al, supra note 111; Shah et al, supra note 111; Luo et al, supra note 111 . 
lost or misinterpreted in the process. An example: as I researched this article, I located the website for a newer advocacy group that has mapped out the legal and policy landscape in Canada. The group's map indicated that Alberta is the only jurisdiction in Canada where a minor must have parental consent to obtain abortion services. There is no such legal requirement in Alberta. This is a serious error, and one can only imagine its potential impact on young women seeking information about abortion services. ${ }^{119}$

These concerns and data gaps demonstrate that data collection must be a government responsibility. We cannot rely on academic researchers to keep us up to date, nor on organizations that rely on grant funding and private donations to keep operating. The best data collection agency is one that is properly resourced and permanent, with a mandate to collect, analyze, and report on sexual and reproductive health information. We already have an organization that could fulfill this role: the Canadian Institute for Health Information (CIHI). CIHI is an independent, not-for-profit organization that was established in 1994 by agreement among the federal, provincial, and territorial governments. ${ }^{120}$ Its purpose is "to improve the 'deplorable state['] of health information ... in Canada." ${ }^{21}$ CIHI does collect some reproductive health-related statistics, such as data on induced abortions in Canada. But as $\mathrm{CIHI}$ itself notes in these reports, the data set is incomplete because non-hospital abortions are reported on a voluntary basis and not all clinics submit information to CIHI. ${ }^{122}$ Moreover, some provinces only report abortions that are covered by the province's own healthcare insurance plan. ${ }^{123}$ CIHI's mandate - to provide health information that leads to improvement in health system performance and population health — certainly seems sufficiently broad to include collection of all of the various kinds of sexual and reproductive health data that we need. At a minimum, it can be a starting point.

In addition to collecting good data that will permit the identification of problem areas, there are numerous steps that can be taken in order to improve access to sexual and reproductive health services. One clearly identifiable, remediable issue is the regulatory process itself. Health Canada must make efforts to identify the cause(s) of delays in the approval of new contraceptive methods and products, and take steps to ensure that approval times for these drugs are in keeping with timelines for other medications and medical products. The Health Canada rules that make applications for Canadian approval unattractive to contraceptive manufacturers must be revisited. If it can be responsibly concluded that the vast amount of data available from older studies (or from studies and clinical use in other jurisdictions) show that a product is safe and effective, then Health Canada should consider relaxing the rules in order to permit Canadian women access to these products.

119 When the organization became aware that this information was incorrect, the error was immediately corrected.

120 Canadian Institute for Health Information, CIHI's Strategic Plan, 2016 to 2021 (CIHI, 2016), online: $<$ https://www.cihi.ca/en/strategicplan2016-2021-enweb.pdf $>$.

121 Ibid at 8, citing National Health Information Council, Health Information for Canada, 1991: Report of the National Task Force on Health Information (Ottawa: NHIC, 1991), Preface at 2, online: $<$ www.statcan.gc.ca/pub/4220352-eng.pdf $>$.

122 Canadian Institute for Health Information, "Quick Stats: Induced Abortions Reported in Canada in 2014," online: $<$ https://www.cihi.ca/sites/default/files/document/induced_abortion_can_2014_en_web. $\mathrm{xlsx}>$.

123 Ontario clinic data and Quebec data only include abortions covered by the province's healthcare insurance plans. This means (for example) that if an Alberta resident received abortion services in Quebec, the procedure would not be reported. 
Funding for contraception and abortion require urgent policy attention. While some Canadian women can obtain some contraceptive products at low or no cost, there are many gaps in public funding. In the UK, all contraceptive products are provided free of charge through family planning clinics and general practitioners. ${ }^{124}$ This approach has been shown to be cost-effective, ${ }^{125}$ in addition to playing an obvious role in helping to reduce unintended pregnancy rates and the incidence and costs of abortion. ${ }^{126}$ Likewise, abortion services should be readily available and funded by the public system, regardless of whether the services are provided in hospital or at a private clinic. Provincial and territorial governments must try to find ways to remove, or at least ameliorate, existing regional differences in availability of abortion services so that all Canadian women have meaningful access.

In consultation with professional regulators, provincial and territorial governments must urgently consider the creation of clear rules around provider conscientious objection related to contraceptive and abortion services. These rules must make it clear that although ideally, providers should be free to refrain from participation in procedures that are at odds with their personal moral or religious views, providers' right to object cannot be absolute. In managing conflicts between the rights of providers and patients, priority must go the patient.

Most of these initiatives will require some degree of collaboration among Canada's federal and regional governments. Nowhere is this need more pressing than with respect to improving access to reproductive health care for Aboriginal women. The federal and regional governments share responsibility for delivery of health care services to Aboriginal Canadians; in part the divide relates to status under the Indian Act, and in part it depends on where the individual lives. ${ }^{127}$ The jurisdictional divide itself is partly to blame for the access problems faced by these women. ${ }^{128}$ As access improves for non-Aboriginal Canadian women, Aboriginal women will share in that benefit. But there are additional issues specifically related to sexual and reproductive health for Aboriginal women that will require sustained, collective efforts by both levels of government. Attention to these concerns will not only improve the lives of Aboriginal Canadians in general, but it will also provide important autonomy and equality related benefits to women and children.

\section{CONCLUSION}

The challenges confronting Canadian women seeking to access sexual and reproductive health care appear minor in scale when compared to the formidable and persistent access issues that face women in developing regions. But it is no answer to a pregnant woman desperate to secure an abortion that her problems could be much worse. Perhaps surprisingly,

Emily Jackson, Regulating Reproduction: Law, Technology and Autonomy (Oxford: Hart, 2001) at 16. See Black et al, "Guideline 329," supra note 23 at S8; A McGuire \& D Hughes, "The Economics of Family Planning Services: A Report Prepared for the Contraceptive Alliance" (London, UK: Contraceptive Alliance, 1995); UK, Department of Health, Choosing Health: Making Healthy Choices Easier, Cm 6374 (London: The Stationery Office, November 2004); UK, Department of Health, Findings of the Baseline Review of Contraceptive Services (London: Department of Health, May 2007) at 7, online: <www.dh.gov.uk/en/Publicationsandstatistics/Publications/PublicationsPolicyAndGuid ance/DH_074727>; Kelly Cleland et al, "Family Planning as a Cost-Saving Preventive Health Service"

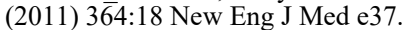

Black et al, supra note 23 at S5-S7.

RSC 1985, c I-5. See also MacIntosh, supra note 103 at 584-97 (for a detailed discussion). MacIntosh, ibid at $584-88$. 
and in spite of Canada's relatively progressive legal regime, Canadian women do confront difficulties accessing sexual and reproductive health care. The good news is that many of the issues I have identified here can be resolved through some focused policy attention and cooperation between federal and regional governments. It is an easy fix, for example, to mandate reporting by abortion clinics, or to remove unnecessary restrictions on the availability of Mifegymiso. Ideally, the end result of a collaborative approach to making policy around access to care will be the development and implementation of a coordinated policy strategy to advance women's sexual and reproductive health and rights.

Unfortunately, it has been difficult to attract policy attention to focus on improving women's access to sexual and reproductive health services. For a decade, Canada had a federal government that apparently had no interest in making policy in this area. But we have recently had a change in government, one that signals reason to be optimistic that we can start to identify and address problems with access to sexual and reproductive health care. Prime Minister Justin Trudeau generated international headlines when he named a cabinet made up of equal numbers of men and women. When he was asked why gender parity was a priority, he responded, "Because it's 2015."129 It is time to start asking when the government will begin applying this same logic to women's sexual and reproductive rights. 